\title{
SARS-CoV-2 Clinical Characteristics and Viral Shedding in Kuwait
}

\author{
Mohammad Alghounaim ${ }^{\mathrm{a}}$ Chelsea Caya ${ }^{\mathrm{b}}$ Khalid Alothman ${ }^{\mathrm{c}}$ \\ Almonther Alhasawi $^{d}$ Jesse Papenburg ${ }^{\mathrm{e}, f}$
}

aDepartment of Pediatrics, Amiri Hospital, Ministry of Health, Kuwait, Kuwait; bMcGill University Health Centre Research Institute, Montreal, QC, Canada; 'Department of Pediatrics, Jaber Alahmad Hospital, Ministry of Health, Kuwait, Kuwait; ${ }^{d}$ Department of Medicine, Infectious Diseases Hospital, Ministry of Health, Kuwait, Kuwait; 'Division of Pediatric Infectious Diseases, The Montreal Children's Hospital, McGill University Health Centre, Montreal, QC, Canada; ${ }^{\mathrm{D}}$ ivision of Microbiology, Department of Laboratory Medicine, McGill University Health Centre, Montreal, QC, Canada

\section{Highlights of the Study}

- This study was aimed at estimating the duration of SARS-CoV-2 shedding among infected patients in Kuwait and to describe the clinical characteristics among SARS-CoV-2 infections.

- More than half of the SARS-CoV-2-infected patients in this study were asymptomatic.

- Duration of RT-PCR positivity varied across disease severity categories.

- Severe COVID-19 cases had lower lymphocyte counts and higher levels of C-reactive protein and procalcitonin.

- Age, acute respiratory syndrome, and low white blood cells were associated with longer RT-PCR positivity.

\section{Keywords}

Severe acute respiratory syndrome-related coronavirus-2 . Coronavirus disease-19 · Epidemiology · Hospitalization . Shedding

\footnotetext{
Abstract

Objectives: We aimed to describe the clinical characteristics of SARS-CoV-2 infection and estimate viral shedding duration in respiratory specimens. Methods: A retrospective cohort study was performed from February 25 to March 25, 2020. In Kuwait, all suspected coronavirus disease 2019 (COVID-19) cases, contacts of cases, and returning travelers were systematically tested for SARS-CoV-2 by RT-PCR. All infected
}

persons, regardless of symptoms, were hospitalized and serially tested until they had two negative results. Descriptive statistics and regression analyses were performed. Results: Two hundred seven cases of SARS-CoV-2 infection were included in this study. About half of the cases were asymptomatic and $1.9 \%$ died. The median time to negative RT-PCR was 22 days. Increasing age, ARDS, and low peripheral white blood cell count were associated with prolonged PCR positivity. Conclusion: Predictors for prolonged RT-PCR positivity included increasing age, ARDS, and low white blood cell count. The findings of this study may aid in better understanding of the epidemiology of SARS-CoV-2 infection and molecular testing dynamics.

(C) 2021 The Author(s)

Published by S. Karger AG, Basel karger@karger.com www.karger.com/mpp

Karger $\stackrel{\text { ' }}{5}$

BOPEN ACCESS
(C) 2021 The Author(s)

Published by S. Karger AG, Basel

This is an Open Access article licensed under the Creative Commons Attribution-NonCommercial-4.0 International License (CC BY-NC) (http://www.karger.com/Services/OpenAccessLicense), applicable to the online version of the article only. Usage and distribution for commercial purposes requires written permission.
Correspondence to:

Mohammad Alghounaim, malghounaim@moh.gov.kw 


\section{Introduction}

Severe acute respiratory syndrome-related coronavirus 2 (SARS-CoV-2) is a novel betacoronavirus and the causative agent of coronavirus disease 2019 (COVID-19). Disease severity ranges from asymptomatic infection to acute respiratory distress syndrome (ARDS) and respiratory failure; however, the exact proportion of each clinical category is not fully known [1]. For instance, the reported prevalence of asymptomatic persons among SARS-CoV-2 infections has ranged from 6.3 to $96.0 \%$ [2-4].

To limit community transmission, several countries, including Kuwait, adopted isolation measures for all cases of SARS-CoV-2 infection until they are no longer considered infectious as demonstrated by 2 consecutive negative real-time polymerase chain reaction (RT-PCR) results from respiratory specimens $[5,6]$. We aimed to estimate the duration of SARS-CoV-2 shedding among infected patients in Kuwait using RT-PCR from paired nasopharyngeal and oropharyngeal specimens. Our secondary objective was to describe the clinical characteristics among SARS-CoV-2 infections.

\section{Methods}

We performed a national, single-center retrospective cohort study at Jaber Alahmad Hospital (JAH) of the Ministry of Health, Kuwait. Patients admitted from February 25 to March 25, 2020, with SARS-CoV-2 infection were followed until discharge. During the study period, by ministerial decree, all persons with COVID-19 symptoms, returning travelers, and close contacts of SARS-CoV-2 cases were tested for SARS-CoV-2 by RT-PCR. All confirmed cases were admitted to JAH regardless of their symptoms until they had 2 consecutive negative RT-PCR results. On April 15, 2020, patient discharge policy was changed due to limits in bed capacity, and patients were given the option to be discharged to institutional quarantine. Patient charts were reviewed to obtain relevant clinical and laboratory data. Disease severity categorization was based on the WHO classification [1].

Paired nasopharyngeal and oropharyngeal swabs were collected routinely as per the discretion of the treating team, typically every 3-5 days throughout the admission. Nucleic acid extraction and RT-PCR were performed on MagNA Pure and Light Cycler 480 (Roche $^{\mathrm{TM}}$, Basel, Switzerland). RT-PCR cycle threshold (Ct) value for the $\mathrm{E}$ and RdRP gene targets was measured using Tib MolBiol's LightMix (Roche ${ }^{\mathrm{TM}}$, Basel, Switzerland).

Descriptive statistics were performed. Patients with severe COVID-19 as per WHO classification (severe pneumonia, ARDS, and sepsis/septic shock) were compared to those with asymptomatic or mild infection using $\chi^{2} /$ Fisher's exact test or Wilcoxon test as appropriate. Predictors for duration of RT-PCR positivity were estimated using negative binomial regression. Multiple imputation using the MICE package in $\mathrm{R}$ was performed to estimate missing values for time to negativity.

\section{Results}

During the study period, we identified 207 SARSCoV-2 hospitalizations in Kuwait. Median age of patients was 48.9 (IQR 28.9-60.5) and 48.8\% were males (Table 1). Approximately half of the patients (51.7\%, 95\% CI: 44.9$58.4 ; 46.7 \%$ of these patients were male) did not develop COVID-19 symptoms prior to, or during, their hospitalization. When compared with asymptomatic or mild infections, patients with severe disease had longer median hospital LOS (37 vs. 25 days; $p<0.001$ ) and were more likely to have comorbid conditions $(83.3 \%$ vs. $47.6 \%$; $p=$ $0.008)$ and to be prescribed antibiotics ( $100.0 \%$ vs. $16.4 \%$; $p<0.001)$. One patient with mild COVID-19 was admitted to the ICU for reasons not related to the infection and did not require respiratory support. Four patients died (1.9\%, 95\% CI: 0.75-4.8).

On admission, patients with severe disease had lower median lymphocyte count $(1.20$ vs. $1.85 ; p<0.001)$ and higher C-reactive protein (33.0 vs. $5.0 ; p<0.001)$ and procalcitonin $(0.115$ vs. $0.046 ; p<0.001)$ levels. Co-infections were uncommon. Four patients had documented bacterial or fungal infection ( 3 bacteremia, 1 candidemia, 2 urinary tract infection, and 2 ventilator-associated pneumonia).

Time to 2 negative consecutive RT-PCR results was 22 days (IQR 14.75-27) among asymptomatically infected subjects. Viral shedding was significantly longer in severe disease (31 days [IQR 26-36.5]) compared to mild disease/asymptomatic infection (22 days [IQR 15-27.5]; $p=$ 0.001). Increasing age, ARDS, and low peripheral WBC count were significant predictors for longer time to negative RT-PCR in multivariable analysis (Table 2).

Of the study population, 53 subjects were discharged earlier to an institutional quarantine and, hence, did not fulfill the criteria for 2 consecutive negative RT-PCR, and missing values were imputed. Also, imputation of missing values of CRP $(n=5)$, PCT $(n=15)$, and date of discharge $(n=1)$ was performed.

\section{Discussion}

In this national study of SARS-CoV-2 infections, we observed prolonged RT-PCR positivity with median duration ranging from 19.5 to 40 days across disease severity categories. Older age, ARDS, and low WBC were significantly associated with prolonged PCR positivity in a multivariable model.
Med Princ Pract 2022;31:93-97 DOI: $10.1159 / 000521408$
Alghounaim/Caya/Alothman/Alhasawi/ Papenburg 


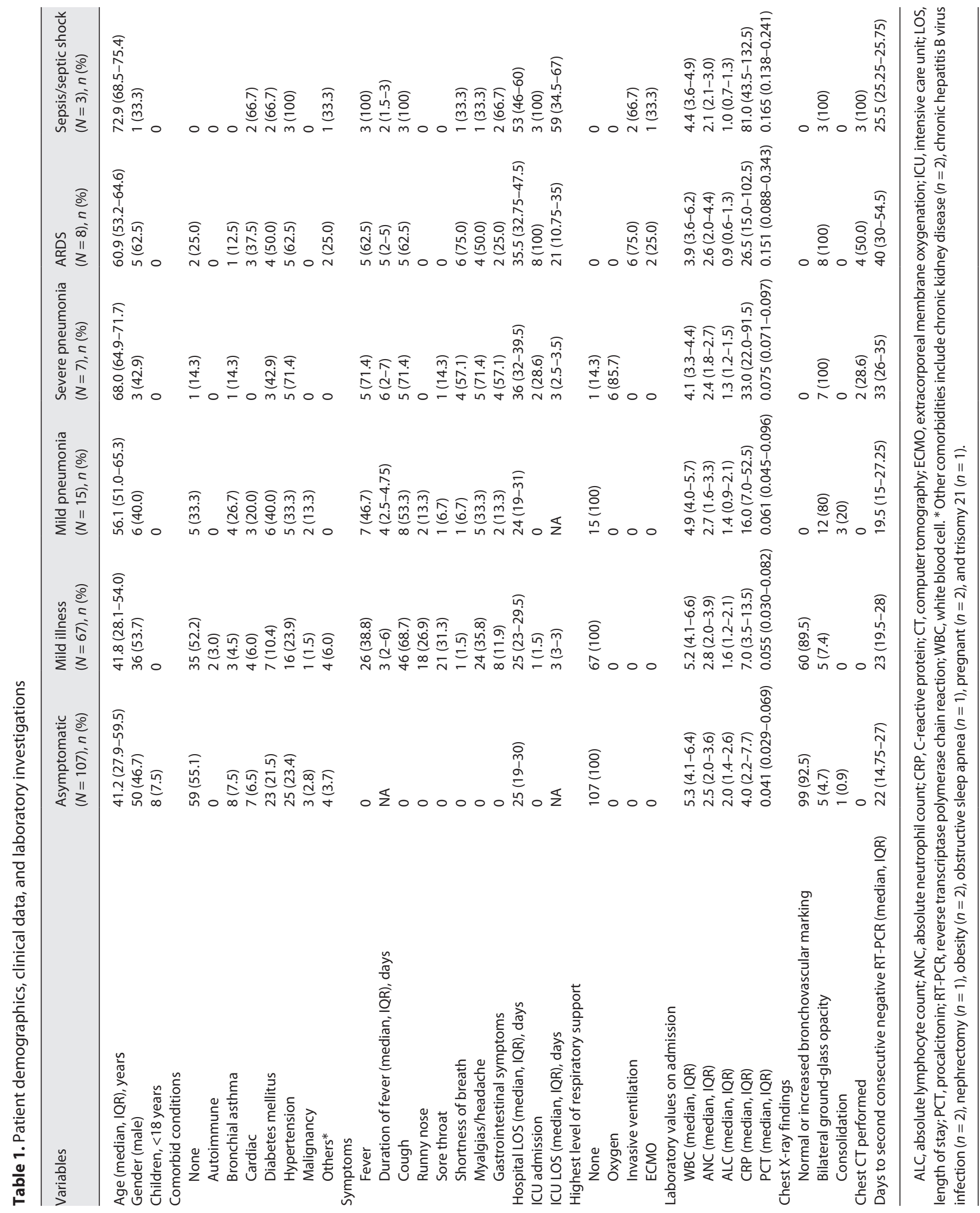


Table 2. Negative binomial regression analyses to identify predictors for time to RT-PCR negativity

\begin{tabular}{|c|c|c|c|c|}
\hline \multirow[t]{2}{*}{ Covariate } & \multicolumn{2}{|l|}{ Univariable } & \multicolumn{2}{|c|}{ Multivariable model } \\
\hline & coefficient & $95 \% \mathrm{Cl}$ & coefficient & $95 \% \mathrm{Cl}$ \\
\hline Age & 1.004 & $1.001-1.007$ & 1.004 & $1.000-1.008$ \\
\hline Male gender & 0.983 & $0.878-1.099$ & N/A & \\
\hline \multicolumn{5}{|l|}{ Disease severity } \\
\hline Asymptomatic & Reference & & Reference & \\
\hline Mild illness & 1.062 & $0.939-1.201$ & 1.124 & $0.986-1.283$ \\
\hline Mild pneumonia & 0.934 & $0.751-1.169$ & 0.924 & $0.738-1.161$ \\
\hline Severe pneumonia & 1.417 & $1.059-1.924$ & 1.196 & $0.870-1.662$ \\
\hline ARDS & 1.223 & $0.926-1.636$ & 1.792 & $1.287-2.542$ \\
\hline Sepsis/septic shock & 0.887 & $0.559-1.446$ & 1.069 & $0.654-1.801$ \\
\hline \multicolumn{5}{|c|}{ Peripheral blood laboratory values on admission } \\
\hline C-reactive protein & 0.999 & $0.998-1.001$ & N/A & \\
\hline Procalcitonin & 0.555 & $0.333-0.935$ & $\mathrm{~N} / \mathrm{A}$ & \\
\hline White blood cell count & 0.948 & $0.928-0.969$ & 0.957 & $0.934-0.980$ \\
\hline Absolute neutrophil count & 0.925 & $0.895-0.957$ & $\mathrm{~N} / \mathrm{A}$ & \\
\hline Absolute lymphocyte count & 0.964 & $0.933-0.997$ & N/A & \\
\hline
\end{tabular}

Other studies have reported similar durations of viral shedding. Among 137 COVID-19 survivors from Wuhan, median time of RT-PCR positivity was 20.0 days (IQR 17.0-24.0) [7]. In another study, median viral shedding was 31.0 days (IQR 24.0-40.0) without difference in gender or age [8]. Estimation of viral shedding based on RT-PCR positivity was the standard of care at the beginning of the pandemic [5]. However, detectable SARSCoV-2 RNA may not represent viable virus. Recent evidence suggests that SARS-CoV-2 is not isolated from cell culture after 8-10 days of illness onset [9-11]. However, viral detection in cell culture is less sensitive than RTPCR, and cycle threshold value correlates with cultivatable virus $[12,13]$. Hence, further studies examining the duration of viral shedding are needed to better determine the contagious period.

We found that more than half of the SARS-CoV-2 infections were asymptomatic. This may be an accurate reflection of the asymptomatic SARS-CoV-2 infection rate as, during the study period, public health policy dictated that RT-PCR testing be systematically done on all returning travelers and close contacts at least twice: at arrival and after 14 days. Also, asymptomatic patients were all admitted and observed daily for the development of symptoms. Our longitudinal study was thus able to distinguish asymptomatic cases from pre-symptomatic individuals that eventually develop symptoms. Our asymptomatic proportion is much higher than modeling estimates based on European data (17.9\%; 95\% CI:
15.5-20.2\%). However, our findings are in line with a recent review that found that approximately $40 \%-50 \%$ of those infected with SARS-CoV-2 will remain asymptomatic, and that they can transmit the virus for perhaps longer than 14 days $[3,4]$.

Our study was limited by the small number of patients with critical illness. This affected our ability to precisely evaluate the association between duration of viral shedding and disease severity. Also, the majority of patients had RT-PCR performed in a different laboratory prior to admission and some after discharge to quarantine. The $\mathrm{Ct}$ values and results of these tests were not accessible to the authors. Nevertheless, our longitudinal design and systematic screening of all returning travelers and COVID-19 case contacts in Kuwait gives a more accurate estimate of asymptomatic infections.

\section{Conclusion}

Asymptomatic SARS-CoV-2 is common, and the duration of RT-PCR positivity varies according to disease severity, age, and white blood cell counts. The findings of this study shed light on the understanding of the dynamics of results of SARS-CoV-2 molecular testing. Further studies are needed to evaluate the impact of prolonged RT-PCR positivity on public health measures.
Alghounaim/Caya/Alothman/Alhasawi/ Papenburg 


\section{Statement of Ethics}

This study was approved by the Ethics Board of the Ministry of Health (2020/1408).

\section{Conflict of Interest Statement}

J.P. has received consulting/honoraria fees from AbbVie, Cepheid, and Seegene and research grant funding outside of the current study from AbbVie, BD Diagnostics, Sanofi Pasteur, and MedImmune.

\section{Funding Sources}

This research did not receive any specific grant from funding agencies in the public, commercial, or not-for-profit sectors.

\section{Author Contributions}

Mohammad Alghounaim contributed to conceptualization, methodology, investigation, data curation, and writing original draft; Chelsea Caya contributed to data curation, formal analysis, and writing - review and editing; Khalid Alothman contributed to conceptualization, methodology, and writing - review and editing; Almonther Alhasawi contributed to methodology, investigation, and writing - review and editing; Jesse Papenburg contributed to conceptualization, methodology, formal analysis, and writing - review and editing.

\section{Data Availability Statement}

Data are available on request.

\section{References}

1 World Health Organization. Clinical management of severe acute respiratory infection when COVID-19 is suspected: interim guidance V1.2; 2020. Available from: https:// www.who.int/publications/i/item/clinicalmanagement-of-covid-19.

2 Mizumoto K, Kagaya K, Zarebski A, Chowel G. Estimating the asymptomatic proportion of coronavirus disease 2019 (COVID-19) cases on board the diamond princess cruise ship, Yokohama, Japan, 2020. Euro Surveill. 2020: 25.

3 Nishiura H, Kobayashi T, Miyama T, Suzuki A, Jung SM, Hayashi K, et al. Estimation of the asymptomatic ratio of novel coronavirus infections (COVID-19). Int J Infect Dis. 2020 May; $94: 154$.

4 Oran DP, Topol EJ. Prevalence of asymptomatic SARS-CoV-2 Infection: a narrative review. Ann Intern Med. 2020:M20-3012.

5 Wong JEL, Leo YS, Tan CC. COVID-19 in Singapore-current experience: critical global issues that require attention and action. JAMA. 2020;323(13):1243.
6 Xiao AT, Tong YX, Gao C, Zhu L, Zhang YJ, Zhang S. Dynamic profile of RT-PCR findings from 301 COVID-19 patients in Wuhan, China: a descriptive study. J Clin Virol. 2020; 127:104346

7 Zhou F, Yu T, Du R, Fan G, Liu Y, Liu Z, et al. Clinical course and risk factors for mortality of adult inpatients with COVID-19 in Wuhan, China: a retrospective cohort study. Lancet. 2020;395:1054-62.

8 Zhou B, She J, Wang Y, Ma X. The duration of viral shedding of discharged patients with severe COVID-19. Clin Infect Dis. 2020; 71(16):2240.

9 La Scola B, Le Bideau M, Andreani J, Hoang VT, Grimaldier C, Colson P, et al. Viral RNA load as determined by cell culture as a management tool for discharge of SARS-CoV-2 patients from infectious disease wards. Eur J Clin Microbiol Infect Dis. 2020;39:1059-61.
10 Million M, Lagier JC, Gautret P, Colson P, Fournier PE, Amrane S, et al. Early treatment of COVID-19 patients with hydroxychloroquine and azithromycin: a retrospective analysis of 1061 cases in Marseille, France. Travel Med Infect Dis. 2020:101738.

11 Bullard J, Dust K, Funk D, Strong JE, Alexander D, Garnett L, et al. Predicting infectious SARS-CoV-2 from diagnostic samples. Clin Infect Dis. 2020;71(10):2663.

12 AlGhounaim M, Xiyo Y, Caya C, Papenburg B. Diagnostic yield and clinical impact of routine cell culture for respiratory viruses among children with a negative multiplex RT-PCR result. J Clin Virol. 2017;94:107-9.

13 Singanayagam A, Patel M, Charlett A, Lopez Bernal J, Saliba V, Ellis J, et al. Duration of infectiousness and correlation with RT-PCR cycle threshold values in cases of COVID-19, England, January to May 2020. Euro Surveill. 2020;25(32):2001483. 